\title{
BMJ Open Association between vitamin D and fatigue in patients with rheumatoid arthritis: a cross-sectional study
}

\author{
Lars Petter Jelsness-Jørgensen (1) , , ${ }^{1,2}$ Lars Grøvle, ${ }^{3}$ Anne Julsrud Haugen ${ }^{3}$
}

To cite: Jelsness-Jørgensen LP, Grøvle L, Julsrud Haugen A. Association between vitamin $D$ and fatigue in patients with rheumatoid arthritis: a crosssectional study. BMJ Open 2020;10:e034935. doi:10.1136/ bmjopen-2019-034935

- Prepublication history for this paper is available online. To view these files, please visit the journal online (http://dx.doi org/10.1136/bmjopen-2019034935).

Received 11 October 2019 Revised 18 December 2019 Accepted 20 January 2020
Check for updates

(c) Author(s) (or their employer(s)) 2020. Re-use permitted under CC BY-NC. No commercial re-use. See rights and permissions. Published by BMJ.

${ }^{1}$ Internal Medicine, Sykehuset Ostfold HF, Sarpsborg, Norway ${ }^{2}$ Health Sciences, Østfold University College, Fredrikstad, Norway

${ }^{3}$ Rheumatology, Sykehuset Ostfold HF, Sarpsborg, Norway

\section{Correspondence to}

Dr Lars Petter JelsnessJørgensen;

lars.p.jelsness-jorgensen@ hiof.no

\section{ABSTRACT}

Objectives In rheumatoid arthritis (RA), fatigue is an important complaint with a significant impact on quality of life. Vitamin D has modulatory effects on cells of the immune system and may potentially affect RA disease activity and thereby RA-related fatigue. The purpose of this study was to explore associations between fatigue and vitamin $D$ status in patients with $R A$.

Design Hypothesis-generating cross-sectional study. Setting Scheduled follow-up visits at a hospital-based general rheumatology clinic.

Participants Patients $(n=169)$ with established RA. Primary outcome measures and anlyses Fatigue, assessed by the Chalder fatigue questionnaire, and serum concentrations of 25-hydroxyvitamin D $(25(\mathrm{OH})$ D), assessed by liquid chromatography-tandem mass spectrometry. Associations were analysed by correlation, and multivariate linear regression with adjustments for age, sex, body mass index, RA disease activity as measured by the Disease Activity Score 28-joint count C reactive protein (DAS28-CRP), psychological distress, pain and sleep. Fatigue was also compared across four groups based on the levels of serum $25(\mathrm{OH}) \mathrm{D}$ with cut points at 30,50 and $75 \mathrm{nmol} / \mathrm{L}$ using one-way analysis of variance. Results Two-thirds of the patients (116/169, 69\%) were classified with low RA disease activity, that is, a DAS28-CRP score below 3.2. Their mean (SD) serum 25(OH)D concentration was 56.3 (21.2) nmol/L, with 77 $(45.6 \%)$ having values below $50 \mathrm{nmol} / \mathrm{L}$ and 12 patients $(7.1 \%)$ below $30 \mathrm{nmol} / \mathrm{L}$. The correlation between fatigue and serum concentrations of $25(\mathrm{OH}) \mathrm{D}$ was weak and not statistically significant, $r=-0.14(95 \% \mathrm{Cl}:-0.29$ to $0.03, p=0.08$ ). In the multivariate model, fatigue was significantly associated with RA disease activity, psychological distress and pain, but not with serum $25(\mathrm{OH})$ D. Fatigue did not differ across groups with varying levels of serum 25(OH)D.

Conclusion This cross-sectional study found no evidence of association between vitamin $D$ and fatigue in patients with RA.

\section{BACKGROUND}

In rheumatoid arthritis (RA), fatigue is an important complaint with a significant impact on quality of life. ${ }^{1}$ RA patients rank fatigue as one of their most disabling symptoms, and measures of fatigue provides information central to the understanding of the outcome

\section{Strengths and limitations of this study}

This study used validated measures of fatigue, rheumatoid arthritis (RA) disease activity, pain, sleep and psychological distress, and vitamin D status was analysed by liquid chromatography-tandem mass spectrometry.

- The variability in fatigue scores and serum 25-hydroxyvitamin D was substantial, ensuring robust correlation and regression analyses.

- The sample $(n=169)$ was representative for patients with established RA; nearly all patients received disease-modifying antirheumatic drug treatment, and 89\% met the 2010 American College of Rheumatology/European League Against Rheumatism (ACR/EULAR) classification criteria for RA when applied retrospectively.

- The study was performed at a single centre using a sample of convenience.

of this disease. ${ }^{23}$ The cause of fatigue in RA is not well known; studies on the relationship with inflammation have yielded inconsistent results and many patients continue to experience fatigue even after achieving remission or low disease activity. ${ }^{45}$ In patients with RA, as well as in other clinical conditions and in the general population, fatigue correlates with pain, anxiety, depression, sleep disturbance and obesity. ${ }^{6-10}$

Vitamin D has both direct and indirect modulatory effects on cells of the immune system. ${ }^{11}$ It has been hypothesised that vitamin $\mathrm{D}$ deficiency could contribute to increased immune activation, thus playing a role in RA pathogenesis. ${ }^{12}$ Systematic reviews have found evidence for a negative association between serum vitamin $\mathrm{D}$ and RA disease activity. ${ }^{1314}$ Whether vitamin D status is linked to fatigue in RA is unknown.

An established marker for vitamin D status is the serum concentration of 25-hydroxyvitamin D $(25(\mathrm{OH}) \mathrm{D})$, representing both dietary and skin-synthetised vitamin D. Currently no consensus exists on the optimal level of serum of $25(\mathrm{OH})$ D. Suggested thresholds for 
vitamin D deficiency vary from 30 to $50 \mathrm{nmol} / \mathrm{L}$, whereas serum concentrations between 50 and $75 \mathrm{nmol} / \mathrm{L}$ have been suggested to represent vitamin D insufficiency. ${ }^{15-18}$ Of note, $1 \mathrm{nmol} / \mathrm{L} 25(\mathrm{OH}) \mathrm{D}$ corresponds to $0.4 \mathrm{ng} / \mathrm{mL}$.

While vitamin D status in RA patients has been investigated with regard to depression and anxiety, ${ }^{19}$ studies into the potential association with fatigue remain scarce. Since effective interventions against fatigue remain elusive, there is a need for hypothesis-generating research into potential modifiable sources of fatigue in RA. The aim of the current study was to explore cross-sectional associations between fatigue and vitamin $\mathrm{D}$ status in patients with RA.

\section{METHODS}

\section{Patient and public involvement}

Patients or the public were not involved in the design of the study.

\section{Patients, setting and procedures}

This cross-sectional study took place at the Department of Rheumatology, Østfold Hospital Trust, a general rheumatology clinic in south-east Norway responsible for services for approximately 300000 people. Patients were consecutively recruited by the hospital staff during scheduled follow-up visits to the clinic. Written informed consent was obtained from all participants. Inclusion criteria were age $\geq 18$ years, a clinical diagnosis of RA and ability to read and understand Norwegian. Clinical information from history and examination was collected and reported by trial care givers (physicians or nurses) at the inclusion in the study. The recruitment started in September 2013 and was completed in June 2015. All data were collected at the date of inclusion in the study.

\section{Instruments and assessments}

\section{Background and clinical characteristics}

Patients provided information on their educational, work and smoking status. Years since the diagnosis of RA and current disease-modifying antirheumatic drug (DMARD) treatment, including oral glucocorticoids, were obtained from patients' medical records.

The 2010 ACR/EULAR classification criteria for RA $^{20}$ were retrospectively applied by chart review by an experienced rheumatologist $(\mathrm{AJH})$, using a score of $\geq 6$ to classify definite RA. RA disease activity was assessed by the Disease Activity Score 28-joint count C reactive protein (DAS28-CRP) based on the number of swollen and tender joints, a visual analogue scale of general health and $\mathrm{C}$ reactive protein $(\mathrm{CRP} ; \mathrm{mg} / \mathrm{L}) .{ }^{21}{ }^{22}$ The DAS28-CRP ranges from 0 to 9.4 , scores below 3.2 are considered representing low disease activity. ${ }^{23}$

Body mass index (BMI) was calculated as weight in kilograms divided by height in square metres.

Psychological distress was assessed by the Hospital Anxiety and Depression Scale (HADS). ${ }^{24} 25$ The HADS consists of one scale for depression and one for anxiety, each comprising seven items which are scored from 0 to 3 . The total score ranges from 0 to 42 , higher scores indicate an increased level of symptoms.

Sleep disturbance was assessed by the first dimension of the Basic Nordic Sleep Questionnaire ${ }^{26}$ ('Have you had difficulties falling asleep during the last 3 months') on a five-point Likert scale ranging from 1 (never or less than once per month) to 5 (every night or almost daily).

Pain severity was assessed by the average pain last 24 hours item of the Brief Pain Inventory ${ }^{27}$ on a numerical rating scale from 0 (no pain) to 10 (pain as bad as you can imagine).

\section{Fatigue}

Fatigue was assessed by the Chalder fatigue questionnaire $(\mathrm{CFQ})^{28}{ }^{29}$ The CFQ asks about fatigue symptoms experienced during the last 4 weeks including two scales, physical fatigue (seven items) and mental fatigue (four items). All items are scored on a four-point Likert scale, and the sum score produces the total fatigue score ranging from 0 to 33. Higher scores indicate more fatigue. The CFQ has been used to assess fatigue in the Norwegian general population and in a variety of clinical settings. ${ }^{30} 31$

\section{Vitamin D measurement}

Serum $25(\mathrm{OH}) \mathrm{D}$ refers to the sum of the concentrations of the metabolites $25(\mathrm{OH}) \mathrm{D}_{2}$ and $25(\mathrm{OH}) \mathrm{D}_{3}$. Analysis with determination of $25(\mathrm{OH}) \mathrm{D}_{2} / \mathrm{D}_{3}$ was performed consecutively at the Hormone laboratory at the Department of Medical Biochemistry, Oslo University Hospital, using an in-house liquid chromatography-tandem mass spectrometry method. In brief, after protein precipitation, 25(OH)D was extracted from samples using phospholipid depletion plates. Separation was achieved by reversed-phase chromatography and the isobaric C3 epimer 3-epi-25 $(\mathrm{OH}) \mathrm{D}_{3}$ was separated from $25(\mathrm{OH})$ $\mathrm{D}_{3}$. Mass spectrometric detection was performed by electrospray ionisation and triple quadruple ion separation (multiple reaction monitoring). The laboratory participated in the Vitamin D External Quality Assessment Scheme ${ }^{32}$ for total $25(\mathrm{OH}) \mathrm{D}$ is accredited by the Norwegian Accreditation as a testing laboratory, and it complies with the general requirements for the competence of testing and calibration laboratories (ISO/IEC 17025:2017). The total analytical variation, expressed as relative $\mathrm{SD}$, was below $13 \%$.

\section{Analysis}

Associations between fatigue and vitamin $\mathrm{D}$ were analysed by correlation (Pearson $\mathrm{r}$ with bootstrap 95\% CI) and multivariate linear regression. The multivariate analysis was performed using total fatigue score as dependent variable, and serum $25(\mathrm{OH}) \mathrm{D}$, age, sex, BMI, RA disease activity, psychological distress, pain and sleep disturbance as independent variables. Assumptions underlying linear regression analysis regarding normality and linearity were adequately met, and all variance inflation factors were below 2 . 
In order to investigate potential threshold effects of serum $25(\mathrm{OH}) \mathrm{D}$ on fatigue, patients were categorised into four groups: (1) $<30 \mathrm{nmol} / \mathrm{L}$, (2) $30-49 \mathrm{nmol} / \mathrm{L}$, (3) $50-74 \mathrm{nmol} / \mathrm{L}$ and $(4) \geq 75 \mathrm{nmol} / \mathrm{L}$. The cut points were based on the increased risk of rickets/osteomalacia at serum levels below $30 \mathrm{nmol} / \mathrm{L}$, and the uncertainty in the literature as to whether $50 \mathrm{nmol} / \mathrm{L}$ or $75 \mathrm{nmol} / \mathrm{L}$ represents safe and sufficient $25(\mathrm{OH}) \mathrm{D}$ levels. A one-way analysis of variance (ANOVA) was conducted to compare fatigue across these groups.

$P$ values $<0.05$ were considered statistically significant; all tests were two-sided. Analyses were performed by IBM SPSS Statistics for windows V25.0 (IBM Corp.).

\section{RESULTS}

In total 208 patients were consecutively invited to participate in the study, of whom $178(86 \%)$ gave written informed consent. Six patients were excluded due to missing data, and three were excluded due to an incorrect RA diagnosis, leaving 169 patients available for analyses.

Clinical and socio-demographic characteristics are presented in table 1 .

The sample included patients with established disease with a median (IQR) disease duration of 9 (4-17.5) years. Nearly all patients $(155 / 169,92 \%)$ received synthetic and/or a biologic DMARD treatment, and/or oral glucocorticoids. Of 22 patients taking oral glucocorticoids, 5 patients did not receive a DMARD. Two-thirds (116/169, $69 \%$ ) were classified with low RA disease activity, that is, a DAS28-CRP score below 3.2. In total 89\% (149/167) met the retrospectively applied 2010 ACR/EULAR classification criteria for RA.

Patients' mean (SD) serum 25(OH)D was 56.3 (21.2) $\mathrm{nmol} / \mathrm{L}$, with $77(46 \%)$ having a serum 25(OH)D concentration below $50 \mathrm{nmol} / \mathrm{L}$ and 12 patients $(7 \%)$ having a serum $25(\mathrm{OH}) \mathrm{D}$ below $30 \mathrm{nmol} / \mathrm{L}$. The mean (SD) fatigue score was $15.2(4.8)$.

The correlation between fatigue and serum concentrations of $25(\mathrm{OH}) \mathrm{D}$ was weak and not statistically significant, $\mathrm{r}=-0.14$ (95\% CI: -0.29 to $0.03, \mathrm{p}=0.08$ ) (figure 1 ). In the multivariate analysis, fatigue was significantly associated with RA disease activity, psychological distress and pain, but not with serum 25(OH)D (table 2). Fatigue scores did not differ across varying levels of serum 25(OH)D (ANOVA; $\mathrm{F}(3.165)=1.05, \mathrm{p}=0.37$ ) (figure 2).

\section{DISCUSSION}

In this cross-sectional study of patients with established $\mathrm{RA}$, fatigue was not associated with vitamin $\mathrm{D}$ status. We are not aware of other studies of vitamin $\mathrm{D}$ and fatigue in RA, but the lack of association is consistent with previous studies in systemic lupus erythematosus, ${ }^{33} 34$ inflammatory bowel disease ${ }^{35}$ and multiple sclerosis. ${ }^{36}$ A Mendelian randomisation study did not find genetic evidence for a causal effect of $25(\mathrm{OH}) \mathrm{D}$ on fatigue. ${ }^{37}$ Vitamin D supplementation did not improve fatigue in patients with breast

\begin{tabular}{|c|c|}
\hline Females, n (\%) & $123(72.8)$ \\
\hline Age, years, mean (SD) & $58.4(11.2)$ \\
\hline $\begin{array}{l}\text { College or university education ( } \geq 4 \text { years), } n \\
\text { (\%) }\end{array}$ & $48(28.4)$ \\
\hline Full-time or part-time work, n (\%) & $51(30.2)$ \\
\hline Current smoker, n (\%) & $23(13.6)$ \\
\hline Body mass index, mean (SD) & $26.4(4.1)$ \\
\hline Years since RA diagnosis, median (IQR) & $9(4.0-17.5)$ \\
\hline DAS28-CRP, mean (SD) & $2.9(1.3)$ \\
\hline $\begin{array}{l}\text { Low RA disease activity (DAS28-CRP<3.2), n } \\
\text { (\%) }\end{array}$ & $116(68.6)$ \\
\hline \multicolumn{2}{|l|}{ Concomitant DMARDs } \\
\hline Synthetic DMARDs only, n (\%) & $69(40.8)$ \\
\hline Synthetic and biologic DMARDs, n (\%) & $60(35.5)$ \\
\hline Biologic DMARDs only, n (\%) & $21(12.4)$ \\
\hline Oral glucocorticoids only, n (\%) & $5(3.0)$ \\
\hline None, n (\%) & $14(8.3)$ \\
\hline 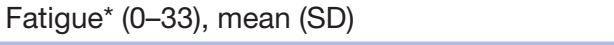 & $15.2(4.8)$ \\
\hline Pain† (0-10), median (IQR) & $4(2-5)$ \\
\hline Sleep disturbance $\neq(0-5)$, median (IQR) & $2(2-3)$ \\
\hline Psychological distress§ (0-42), median (IQR) & $7(3.75-11.0)$ \\
\hline Serum 25(OH)D, nmol/L, mean (SD) & $56.3(21.2)$ \\
\hline \multicolumn{2}{|l|}{ Serum 25(OH)D } \\
\hline$<30 \mathrm{nmol} / \mathrm{L}, \mathrm{n}(\%)$ & $12(7.1)$ \\
\hline 30-49 nmol/L, n (\%) & 65 (38.5) \\
\hline 50-74 nmol/L, n (\%) & $67(39.6)$ \\
\hline$\geq 75 \mathrm{nmol} / \mathrm{L}, \mathrm{n}(\%)$ & $25(14.8)$ \\
\hline
\end{tabular}

${ }^{*}$ Chalder fatigue questionnaire.

†Brief Pain Inventory average pain (last 24 hours).

$\ddagger$ ‡asic Nordic Sleep Questionnaire.

$\S$ Hospital Anxiety and Depression Scale.

CRP, C reactive protein; DAS28-CRP, Disease Activity Score 28-joint count CRP; DMARDs, disease-modifying antirheumatic drugs; 25(OH)D, 25-hydroxyvitamin D; RA, rheumatoid arthritis.

cancer ${ }^{38}$ or chronic fatigue syndrome, ${ }^{39}$ nor in primary care patients with mild to moderate vitamin $\mathrm{D}$ deficiency. ${ }^{40} \mathrm{~A}$ small effect of supplementation was reported in otherwise healthy individuals. ${ }^{41}$

Our results are in line with a well-established association between fatigue and psychological distress. ${ }^{4}$ They also support previous findings of correlation with RA disease activity and pain. ${ }^{6}$ As expected, the mean level of fatigue in this cohort was higher than what has been reported from general population samples. ${ }^{30} 4243$

In this cohort, nearly half of the subjects had serum $25(\mathrm{OH}) \mathrm{D}$ concentrations below $50 \mathrm{nmol} / \mathrm{L}$. Comparing our results with other populations or samples is complicated due to varying sun exposure, skin pigmentation, ethnicity, vitamin D intake/supplementation and analytical methodology. ${ }^{45}$ In two samples from the general Norwegian population, $28 \%$ and $70 \%$ had serum $25(\mathrm{OH})$ 


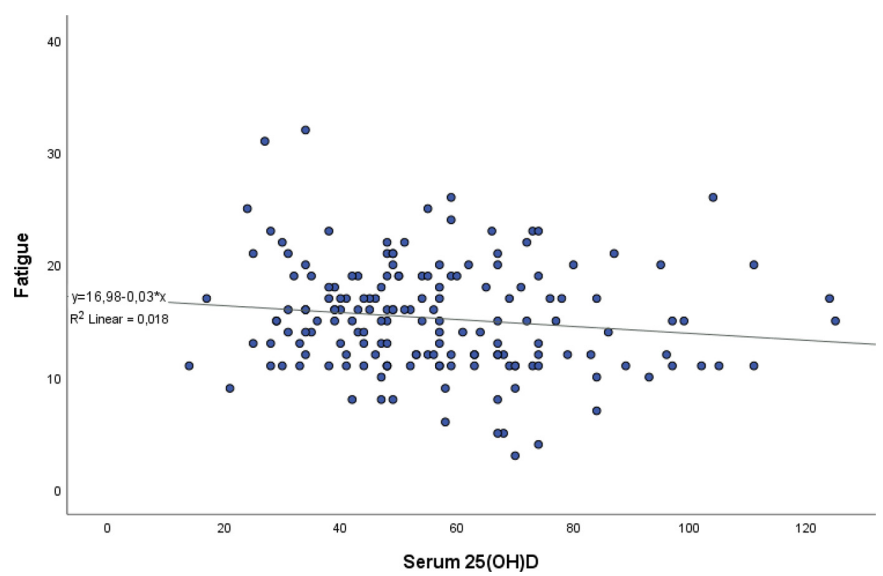

Figure 1 Relationship between fatigue and serum 25(OH)D. 25(OH)D, 25-hydroxyvitamin D.

D below $50 \mathrm{nmol} / \mathrm{L}^{44}{ }^{46}$ Whether RA patients in general have lower levels of $25(\mathrm{OH}) \mathrm{D}$ than healthy controls is unsettled. ${ }^{13} 47$

The strengths of this study are the use of validated measures of fatigue as well as RA disease activity, pain, sleep and psychological distress. Vitamin D status was analysed by liquid chromatography-tandem mass spectrometry, a method considered reference standard in the measurement of serum $25(\mathrm{OH}) \mathrm{D} .^{48}$ It was performed at a single centre using a sample of convenience but we believe that the setting was appropriate for the purpose, namely to generate hypotheses on the association between vitamin $\mathrm{D}$ and fatigue in RA. The proportion of patients who met the 2010 ACR/EULAR classification criteria for RA (89\%) was similar to validation studies using diagnosis by a rheumatologist as reference standard. ${ }^{49}$ Socio-demographic characteristics, disease activity and drug therapy were also very similar to RA patients treated in Norwegian rheumatology clinics at that period. ${ }^{50}$ Furthermore, the variability in fatigue scores and serum $25(\mathrm{OH}) \mathrm{D}$ was substantial, ensuring robust correlation analyses. Among

\begin{tabular}{|c|c|c|c|}
\hline & $\boldsymbol{\beta}$ & $95 \% \mathrm{Cl}$ & $\begin{array}{l}P \\
\text { value }\end{array}$ \\
\hline Serum 25(OH)D & -0.01 & -0.04 to 0.02 & 0.66 \\
\hline Age & -0.03 & -0.08 to 0.03 & 0.31 \\
\hline Sex & -0.26 & -1.59 to 1.06 & 0.70 \\
\hline Body mass index & 0.03 & -0.13 to 0.18 & 0.74 \\
\hline DAS28-CRP & 0.66 & 0.14 to 1.18 & 0.01 \\
\hline Psychological distress* & 0.32 & 0.21 to 0.44 & $<0.001$ \\
\hline Paint & 0.47 & 0.14 to 0.79 & 0.01 \\
\hline Sleep disturbance & 0.11 & -0.47 to 0.69 & 0.71 \\
\hline
\end{tabular}

*Hospital Anxiety and Depression Scale.

†Brief Pain Inventory average pain (last 24 hours).

‡Basic Nordic Sleep Questionnaire.

DAS28-CRP, Disease Activity Score 28 -joint count $C$ reactive

protein; 25(OH)D, 25-hydroxyvitamin D.

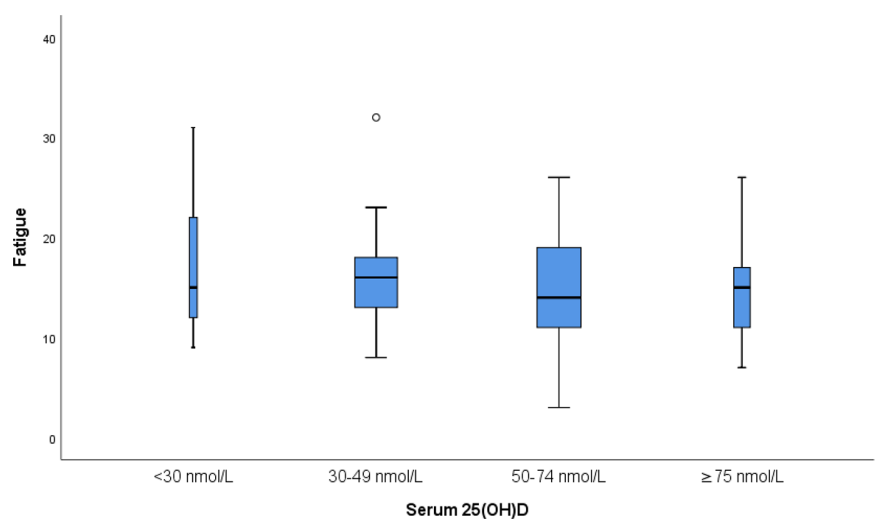

Figure 2 Fatigue according to vitamin D levels. Total range (whiskers), medians (horizontal lines) and 25\%-75\% IQRs (boxes) of fatigue. Box widths are scaled according to counts.

the limitations of this study are those inherent to crosssectional studies such as unknown temporal sequence of associated factors. Our sample included patients with established RA and the results do not apply to those with very early disease.

In conclusion, this hypothesis-generating cross-sectional study found no basis for vitamin $\mathrm{D}$ to be associated with fatigue in patients with established RA.

Twitter Lars Petter Jelsness-Jørgensen @lars_jelsness

Contributors LPJ-J conceived, designed and led the study. AJH acquired the data. LG performed the analyses and wrote the manuscript. All authors participated in the interpretation of the results and critical revision of the manuscript and they gave final approval of the version to be published. LPJ-J is the guarantor of this work and, as such, had full access to all the data in the study and takes responsibility for the integrity of the data.

Funding The authors have not declared a specific grant for this research from any funding agency in the public, commercial or not-for-profit sectors.

Competing interests None declared.

Patient consent for publication Not required.

Ethics approval This study was approved by the Norwegian Regional Ethics Committee South East (2012/845/REK).

Provenance and peer review Not commissioned; externally peer reviewed.

Data availability statement Data are available upon request.

Open access This is an open access article distributed in accordance with the Creative Commons Attribution Non Commercial (CC BY-NC 4.0) license, which permits others to distribute, remix, adapt, build upon this work non-commercially, and license their derivative works on different terms, provided the original work is properly cited, appropriate credit is given, any changes made indicated, and the use is non-commercial. See: http://creativecommons.org/licenses/by-nc/4.0/.

ORCID iD

Lars Petter Jelsness-Jørgensen http://orcid.org/0000-0002-5465-1576

\section{REFERENCES}

1 Rupp I, Boshuizen HC, Jacobi CE, et al. Impact of fatigue on health-related quality of life in rheumatoid arthritis. Arthritis Care Res 2004:51:578-85.

2 Hewlett S, Cockshott Z, Byron M, et al. Patients' perceptions of fatigue in rheumatoid arthritis: overwhelming, uncontrollable, ignored. Arthritis Rheum 2005;53:697-702.

3 Kirwan JR, Minnock P, Adebajo A, et al. Patient perspective: fatigue as a recommended patient centered outcome measure in rheumatoid arthritis. The Journal of rheumatology 2007;34:1174-7. 
4 Nikolaus S, Bode C, Taal E, et al. Fatigue and factors related to fatigue in rheumatoid arthritis: a systematic review. Arthritis Care Res 2013;65:1128-46.

5 Olsen CL, Lie E, Kvien TK, et al. Predictors of fatigue in rheumatoid arthritis patients in remission or in a low disease activity state. Arthritis Care Res 2016;68:1043-8.

6 Katz P. Fatigue in rheumatoid arthritis. Curr Rheumatol Rep 2017;19:25

7 Austad C, Kvien TK, Olsen IC, et al. Sleep disturbance in patients with rheumatoid arthritis is related to fatigue, disease activity, and other patient-reported outcomes. Scand J Rheumatol 2017;46:95-103.

8 Brown LF, Kroenke K. Cancer-related fatigue and its associations with depression and anxiety: a systematic review. Psychosomatics 2009:50:440-7.

9 Fosså SD, Dahl AA, Loge JH. Fatigue, anxiety, and depression in long-term survivors of testicular cancer. J Clin Oncol 2003;21:1249-54.

10 Pawlikowska T, Chalder T, Hirsch SR, et al. Population based study of fatigue and psychological distress. BMJ 1994;308:763-6.

11 Dankers W, Colin EM, van Hamburg JP, et al. Vitamin D in autoimmunity: molecular mechanisms and therapeutic potential. Front Immunol 2016;7:697.

12 Bragazzi NL, Watad A, Neumann SG, et al. Vitamin D and rheumatoid arthritis: an ongoing mystery. Curr Opin Rheumatol 2017;29:378-88.

13 Lin J, Liu J, Davies ML, et al. Serum vitamin D level and rheumatoid arthritis disease activity: review and meta-analysis. PLoS One 2016;11:e0146351.

14 Theodoratou E, Tzoulaki I, Zgaga L, et al. Vitamin D and multiple health outcomes: umbrella review of systematic reviews and meta-analyses of observational studies and randomised trials. BMJ 2014;348:g2035.

15 Binkley N, Dawson-Hughes B, Durazo-Arvizu R, et al. Vitamin D measurement standardization: the way out of the chaos. J Steroid Biochem Mol Biol 2017;173:117-21.

16 Holick MF. Vitamin D deficiency. N Engl J Med 2007;357:266-81.

17 Wu F, Wills K, Laslett LL, et al. Cut-points for associations between vitamin D status and multiple musculoskeletal outcomes in middleaged women. Osteoporos Int 2017;28:505-15.

18 Reid IR, Bolland MJ. Skeletal and nonskeletal effects of vitamin D: is vitamin D a tonic for bone and other tissues? Osteoporos Int 2014;25:2347-57.

19 Pu D, Luo J, Wang Y, et al. Prevalence of depression and anxiety in rheumatoid arthritis patients and their associations with serum vitamin D level. Clin Rheumatol 2018;37:179-84.

20 Aletaha D, Neogi T, Silman AJ, et al. 2010 rheumatoid arthritis classification criteria: an American College of Rheumatology/ European League against rheumatism collaborative initiative. Arthritis Rheum 2010;62:2569-81.

21 Prevoo ML, van 't Hof MA, Kuper $\mathrm{HH}$, et al. Modified disease activity scores that include twenty-eight-joint counts. development and validation in a prospective longitudinal study of patients with rheumatoid arthritis. Arthritis Rheum 1995;38:44-8.

22 Wells G, Becker J-C, Teng J, et al. Validation of the 28-joint Disease Activity Score (DAS28) and European League Against Rheumatism response criteria based on C-reactive protein against disease progression in patients with rheumatoid arthritis, and comparison with the DAS28 based on erythrocyte sedimentation rate. Ann Rheum Dis 2009;68:954-60.

23 Anderson J, Caplan L, Yazdany J, et al. Rheumatoid arthritis disease activity measures: American College of Rheumatology recommendations for use in clinical practice. Arthritis Care Res 2012;64:640-7.

24 Zigmond AS, Snaith RP. The hospital anxiety and depression scale. Acta Psychiatr Scand 1983;67:361-70.

25 Bjelland I, Dahl AA, Haug TT, et al. The validity of the hospital anxiety and depression scale: an updated literature review. J Psychosom Res 2002;52:69-77.

26 Partinen M, Gislason T. Basic Nordic Sleep Questionnaire (BNSQ): a quantitated measure of subjective sleep complaints. J Sleep Res 1995;4:150-5.

27 Cleeland CS, Ryan KM. Pain assessment: global use of the brief pain inventory. Ann Acad Med Singapore 1994;23:129-38.

28 Chalder T, Berelowitz G, Pawlikowska T, et al. Development of a fatigue scale. J Psychosom Res 1993;37:147-53.
29 Morriss R, Wearden A, Mullis R. Exploring the validity of the Chalder fatigue scale in chronic fatigue syndrome. J Psychosom Res 1998;45:411-7.

30 Loge JH, Ekeberg O, Kaasa S. Fatigue in the general Norwegian population: normative data and associations. J Psychosom Res 1998;45:53-65

31 Hewlett S, Dures E, Almeida C. Measures of fatigue. Arthritis Care Res 2011;63:S263-86.

32 Vitamin D external quality assessment scheme. Available: http:// www.deqas.org/ [Accessed 25 Jun 2016]

33 Ruiz-Irastorza G, Egurbide MV, Olivares N, et al. Vitamin D deficiency in systemic lupus erythematosus: prevalence, predictors and clinical consequences. Rheumatology 2008;47:920-3.

34 Stockton KA, Kandiah DA, Paratz JD, et al. Fatigue, muscle strength and vitamin D status in women with systemic lupus erythematosus compared with healthy controls. Lupus 2012;21:271-8.

35 Frigstad SO, Høivik ML, Jahnsen J, et al. Fatigue is not associated with vitamin $\mathrm{D}$ deficiency in inflammatory bowel disease patients. World J Gastroenterol 2018;24:3293-301.

36 Knippenberg S, Damoiseaux J, Bol Y, et al. Higher levels of reported sun exposure, and not vitamin D status, are associated with less depressive symptoms and fatigue in multiple sclerosis. Acta Neurol Scand 2014:129:123-31.

37 Havdahl A, Mitchell R, Paternoster L, et al. Investigating causality in the association between vitamin $D$ status and self-reported tiredness. Sci Rep 2019;9:2880.

38 Khan QJ, Reddy PS, Kimler BF, et al. Effect of vitamin D supplementation on serum 25-hydroxy vitamin D levels, joint pain, and fatigue in women starting adjuvant letrozole treatment for breast cancer. Breast Cancer Res Treat 2010;119:111-8.

39 Witham MD, Adams F, McSwiggan S, et al. Effect of intermittent vitamin D3 on vascular function and symptoms in chronic fatigue syndrome-a randomised controlled trial. Nutr Metab Cardiovasc Dis 2015;25:287-94.

40 Arvold DS, Odean MJ, Dornfeld MP, et al. Correlation of symptoms with vitamin $\mathrm{D}$ deficiency and symptom response to cholecalciferol treatment: a randomized controlled trial. Endocr Pract 2009;15:203-12

41 Nowak A, Boesch L, Andres E, et al. Effect of vitamin D3 on selfperceived fatigue: a double-blind randomized placebo-controlled trial. Medicine 2016;95:e5353

42 Mancuso CA, Rincon M, Sayles W, et al. Psychosocial variables and fatigue: a longitudinal study comparing individuals with rheumatoid arthritis and healthy controls. J Rheumatol 2006;33:1496-502.

43 Smedstad LM, Mourn T, Vaglum P, et al. The impact of early rheumatoid arthritis on psychological distress. Scand J Rheumatol 1996;25:377-82

44 Cashman KD, Dowling KG, Škrabáková Z, et al. Vitamin D deficiency in Europe: pandemic? Am J Clin Nutr 2016;103:1033-44.

45 Roth HJ, Schmidt-Gayk H, Weber H, et al. Accuracy and clinical implications of seven 25-hydroxyvitamin D methods compared with liquid chromatography-tandem mass spectrometry as a reference. Ann Clin Biochem 2008;45:153-9.

46 Standahl Olsen K, Rylander C, Brustad M, et al. Plasma 25 hydroxyvitamin D level and blood gene expression profiles: a crosssectional study of the Norwegian women and cancer post-genome cohort. Eur J Clin Nutr 2013;67:773-8.

47 Kriegel MA, Manson JE, Costenbader KH. Does vitamin D affect risk of developing autoimmune disease?: a systematic review. Semin Arthritis Rheum 2011;40:512-31.

48 Mineva EM, Schleicher RL, Chaudhary-Webb M, et al. A candidate reference measurement procedure for quantifying serum concentrations of 25-hydroxyvitamin D3 and 25-hydroxyvitamin D2 using isotope-dilution liquid chromatography-tandem mass spectrometry. Anal Bioanal Chem 2015;407:5615-24.

49 Radner H, Neogi T, Smolen JS, et al. Performance of the 2010 ACR/ EULAR classification criteria for rheumatoid arthritis: a systematic literature review. Ann Rheum Dis 2014;73:114-23.

50 Ikdahl E, Rollefstad S, Wibetoe G, et al. Feasibility of cardiovascular disease risk assessments in rheumatology outpatient clinics: experiences from the nationwide NOCAR project. RMD Open 2018;4:e000737.

51 Haugeberg G, Hansen IJW, Soldal DM, et al. Ten years of change in clinical disease status and treatment in rheumatoid arthritis: results based on standardized monitoring of patients in an ordinary outpatient clinic in southern Norway. Arthritis Res Ther 2015;17:219. 